\title{
Physical activity in patients with axial spondyloarthritis in a multi-ethnic south-east Asian country
}

\author{
Jie Kie Phang ${ }^{1 \dagger}$, Andrew Yu Keat Khor ${ }^{1 \dagger}$, Yu Heng Kwan ${ }^{1,2}$, Chin Teck Ng ${ }^{1,2}$ and Warren Fong ${ }^{1,2,3^{*}+}$
}

\begin{abstract}
Background: Patients with axial spondyloarthritis (axSpA) may experience spinal stiffness and pain, leading to reduced physical function and quality of life. Despite the benefits of physical activity (PA) and exercise, previous studies have demonstrated lower levels of PA among patients with axSpA. This study aims to examine the patterns of PA among patients with axSpA compared to the general population in a multi-ethnic Asian country.

Methods: This was a cross-sectional study conducted between May 2016 and Jan 2017. Consecutive patients with axSpA were recruited at an outpatient rheumatology clinic at Singapore General Hospital, the largest tertiary hospital in Singapore. Controls were based on a previous cross-sectional study. PA was assessed using the Global Physical Activity Questionnaire (GPAQ).

Results: Seventy-four patients with axSpA were recruited and compared with 2679 controls. Lower proportion of patients with axSpA met the WHO recommendations for PA (axSpA $=77.0 \%$, controls $=89.7 \%, p<0.001)$. More patients with axSpA had high level of sedentary activity compared to controls (axSpA $=56.8 \%$, controls $=36.1 \%$, $p<0.001)$. Levels of PA did not differ between patients with inactive versus active axSpA disease $(p=0.91)$.

Conclusions: Proportion of patients with axSpA meeting the WHO recommendations for PA differed significantly from the general population, and level of PA did not differ between patients with active and inactive axSpA disease. Higher levels of sedentary activity were seen in patient with axSpA compared to the general population, highlighting the need for interventions to promote PA among patients with axSpA.
\end{abstract}

Keywords: Ankylosing spondylitis, Physical activity, Exercise

\section{Introduction}

Patients with axial spondyloarthritis (axSpA) have predominantly inflammatory back pain, and their axial skeleton and sacroiliac joints are often affected [1]. This leads to reduced spinal mobility and function [2], which may result in reduced physical functioning and quality of life (QOL) [3]. In addition, axSpA has also been

\footnotetext{
* Correspondence: warren.fong.w.s@singhealth.com.sg

${ }^{\dagger}$ Jie Kie Phang, Andrew Yu Keat Khor and Warren Fong are co-first authors.

'Department of Rheumatology and Immunology, Singapore General

Hospital, Outram Rd, Singapore 169608, Singapore

2Duke-NUS Medical School, 8 College Rd, Singapore 169857, Singapore

Full list of author information is available at the end of the article
}

shown to have increased risk of cardiovascular disease (CVD), when compared to the general population [4].

Physical activity (PA) and exercise have been shown to improve general well-being and reduce CVD risk in the general population [5]. PA is defined as 'any bodily movement produced by skeletal muscles that result in energy expenditure' [6]. A dose-response relationship between PA and health benefits has also been demonstrated [7]. The World Health Organisation (WHO) has set out recommendations for PA and muscle strengthening activities in adults, including the elderly and people with chronic conditions [8]. The benefits of PA in axSpA

C C The Author(s). 2021 Open Access This article is licensed under a Creative Commons Attribution 4.0 International License, which permits use, sharing, adaptation, distribution and reproduction in any medium or format, as long as you give appropriate credit to the original author(s) and the source, provide a link to the Creative Commons licence, and indicate if changes were made. The images or other third party material in this article are included in the article's Creative Commons licence, unless indicated otherwise in a credit line to the material. If material is not included in the article's Creative Commons licence and your intended use is not permitted by statutory regulation or exceeds the permitted use, you will need to obtain permission directly from the copyright holder. To view a copy of this licence, visit http://creativecommons.org/licenses/by/4.0/ The Creative Commons Public Domain Dedication waiver (http://creativecommons.org/publicdomain/zero/1.0/) applies to the data made available in this article, unless otherwise stated in a credit line to the data. 
have also been shown [9], and the European League Against Rheumatism (EULAR) recommends PA as part of the non-pharmacological management in axSpA [10].

Despite these recommendations, studies show that levels of PA are reduced among patients with axSpA in Canada and Sweden [11, 12]. Based on our best knowledge, there is no study investigating the PA levels among patients with axSpA in Asia. The aim of this paper is to examine the patterns of PA among patients with axSpA compared to the general population in a multi-ethnic Asian country.

\section{Materials and methods}

\section{Study design and population}

This was a cross-sectional study conducted between May 2016 and Jan 2017. Consecutive patients with axSpA were recruited at an outpatient rheumatology clinic at Singapore General Hospital, a tertiary hospital and the largest hospital in Singapore. Inclusion criteria included clinical diagnosis of axSpA, at least 21 years old, and fulfilled the 2009 Assessment of Spondyloarthritis International Society (ASAS) Classification for axSpA classification criteria. Controls were based on a previous population-based cross-sectional Singapore Health 2012 study [13] where random households were selected from the Database of Dwellings, a comprehensive database of all residential dwelling units in Singapore, maintained by the Singapore Department of Statistics. Eligible households who consented to participate in the study received phone calls and household visits followed by an interview.

Demographics such as age, gender, race, body mass index (BMI), smoking status, alcohol status, employment, education level, total monthly household income and comorbidities (hypertension, diabetes mellitus, hyperlipidemia, coronary artery disease, cerebrovascular disease and chronic kidney disease) were collected via a standardised data collection form.

The study was approved by the Institutional Review Board (CIRB 2016/2210) and written informed consent was obtained from all participants.

\section{Assessment \\ Assessment of disease activity and function in patients with axSpA}

Disease activity for axSpA was assessed using Ankylosing Spondylitis Disease Activity Score with C-Reactive Protein (ASDAS-CRP) [14], and function was assessed using the Bath Ankylosing Spondylitis Functional Index (BASFI) [15]. The ASDAS-CRP comprised of back pain, peripheral pain and swelling, duration of morning stiffness, patient global assessment using a 11-point numerical rating scale and the $\mathrm{C}$-reactive protein. Inactive disease was defined as ASDAS $<1.3$, low disease active as ASDAS $\geq 1.3$ and $\leq 2.1$, high disease activity as ASDAS $>2.1$ and $\leq 3.5$ and very high disease activity as ASDAS $>3.5(31)$. The BASFI is a validated index used to determine the degree of functional limitation. It is a selfassessment instrument comprising of 10 questions relating to function and patient's ability to cope with everyday life, with questions answered on a $10 \mathrm{~cm}$ horizontal visual analog scale. Higher BASFI scores indicate greater functional limitation.

\section{Assessment of physical activity}

Physical activity was assessed using the Global Physical Activity Questionnaires (GPAQ) developed by the WHO [16]. Interviewers received training to administer the questionnaires to study participants. The intensity and frequency of moderate-to-vigorous PA (MVPA) was assessed under 3 domains- work, travelling and recreation. Physical activity data was processed and participants were defined as meeting or not meeting recommendations according the cut-offs in the GPAQ analysis guide [16]. We presented the median number of minutes spent on average per day, in work-, transport- and recreationrelated physical activity. Participants who met the WHO recommendations on physical activity were those that achieved (i) $150 \mathrm{~min}$ of moderate-intensity physical activity or (ii) 75 min of vigorous-intensity physical activity or (iii) an equivalent combination of moderate- and vigorousintensity physical activity achieving at least 600 METminutes per week. The level of PA was assessed according to the following criteria [17]:

High: A person reaching any of the following criteria is classified in this category. Vigorous intensity activity on at least three days achieving a minimum of 1500 MET-minutes per week or seven or more days of any combination of walking, moderate- or vigorous-intensity activities achieving a minimum of 3000 MET-minutes per week.

Moderate: A person not meeting the criteria for the 'high' category, but meeting any of the following criteria is classified in this category. Three or more days of vigorous-intensity activity of at least $20 \mathrm{~min}$ per day or five or more days of moderate intensity activity or walking for at least $30 \mathrm{~min}$ per day or five or more days of any combination of walking, moderate- or vigorous-intensity activities achieving a minimum of 600 MET-minutes per week.

Low: A person not meeting any of the abovementioned criteria falls in this category.

Sedentary behaviour was assessed using a single item in the GPAQ (How much time do you usually spend 
sitting or reclining on a typical day?). We defined sedentary as sitting for at least $8 \mathrm{~h}$ per day based on a previous study showing increased all-cause mortality with sitting for at least 8 or more hours per day [18].

\section{Statistical analysis}

Data was tested for normality using Shapiro-Wilk test. Continuous variables were reported as means and standard deviation (SD) if normally distributed, or as median and interquartile range (IQR) if otherwise. Comparison of means were done using student t-test or one-way ANOVAs, or with non-parametric Mann-Whitney U-test or Kruskal-Wallis tests as appropriate. Comparison of medians were performed using nonparametric equality-ofmedians test. Categorical variables were compared using chi-squared tests or Fisher exact test as appropriate. We also performed a sensitivity analysis for median number of minutes spent on average per day, in work-, transportand recreation-related physical activity using sex and age matched controls. Statistical significance was set at $p<0.05$ for all analyses. Analysis was performed using Stata version 15 .

\section{Results}

\section{Socio-demographic characteristics}

Seventy-four patients with axSpA were recruited. They were compared to 2679 controls from the study by Win Am et al. [13]. The socio-demographic characteristics of the participants are presented in Table 1. Patients with axSpA were younger (median age [IQR], 37.0 [26.3] years) as compared to controls (median age [IQR], 51.0 [23.0] years) $(p<0.001)$. Majority of patients with axSpA were male $(75.7 \%)$, which was higher than the proportion of males among the control group (44.8\%) $(p<$ 0.001). There was also a higher percentage of Chinese $(87.8 \%)$ in the axSpA group as compared to controls $(66.6 \%) \quad(p<0.001)$. BMI was similar between the 2 groups (axSpA: median BMI [IQR], 24.1 [5.1]; control: median BMI [IQR], 23.6 [5.5]; $p=0.29$ ). All patients with axSpA were current smokers or ex-smokers (100\%) while majority of controls did not smoke (70.7\%) $(p<$ $0.001)$. None of the participants in the control group had axial spondyloarthritis, whilst $58.8 \%$ self-reported a history of either osteoarthritis of the hip or knee, rheumatoid arthritis or gout.

\section{Physical activity}

Lower proportion of patients with AxSpA met the WHO recommendations for PA $(\mathrm{AxSpA}=77.0 \%$, controls $=89.7 \%, p<0.001)$. In addition, a larger proportion of patients with axSpA were noted to have high levels of sedentary lifestyle compared to controls $(56.8 \%$ vs $36.1 \%$ respectively, $p<0.001$ ).
The median total amount of time spent on physical activity per day did not differ significantly between both groups $(p=0.07)$, but patients with axSpA spent more time on recreational- related physical activity per day (median [IQR], 13.9 [51.4] minutes vs 0 [17.1] minutes, $p=0.01)$ compared to controls. Results from the sensitivity analysis were largely similar (Supplementary Table 1).

\section{Patients with axSpA - inactive vs active disease}

Demographics between patients with axSpA with inactive disease and those with active disease were not statistically different (Table 2). Comorbidities were similar between the inactive and active disease groups.

Proportion of patients who met WHO recommendations for PA did not differ between patients with inactive versus active disease groups $(77.8 \%$ vs $76.6 \%, p=0.907)$, respectively). Patients with axSpA and inactive disease appeared to have higher high levels of PA compared to those with active disease $(51.9 \%$ vs $38.3 \%$ respectively), though this difference was not statistically significant. Proportion of patients with axSpA and high levels of sedentary activity did not differ significantly between inactive and active disease ( $66.7 \%$ vs $51.1 \%, p=0.19)$. Both groups spent more time on recreational activities per day compared to travelling and work.

\section{Discussion}

This study examined the levels of PA among patients with axSpA in multi-ethnic Asian country, Singapore. To our knowledge, this is the first study in South-East Asia looking at PA in patients with axSpA. Our study found that patients with axSpA were less likely to meet WHO recommendations for physical activity but spent more time on recreational-related physical activities, as compared to controls. Patients with axSpA also had higher levels of sedentary behaviour compared to the general population.

In our study, a lower proportion of patients with AxSpA met the WHO recommendations for PA as compared to controls. The literature regarding PA in axial spondylitis has shown mixed results. When using accelometry to measure PA, Swinnen et al. reported lower PA levels in patients with axSpA compared to healthy matched controls [19], while Plasqui et al. reported no statistical difference in PA levels between patients with AS and healthy controls [20]. The cause of lower levels of self-reported physical activity in patients with axSpA could not be elucidated from our study, and further studies will be needed to identify the factors. Previous study had identified physical exertion as the main barrier for exercising among patients with axSpA [21].

The proportion of patients with axSpA who met WHO recommendations for PA in our study was high (77\%) compared to other reported studies. A Swedish 
Table 1 Characteristics and levels of activity of patients with axial spondyloarthritis versus controls

\begin{tabular}{|c|c|c|c|}
\hline Characteristic & $\begin{array}{l}\text { AxSpA } \\
N=74\end{array}$ & $\begin{array}{l}\text { Controls } \\
N=2679\end{array}$ & $P$ value \\
\hline Current age, median (IQR), years & $37.0(26.3)$ & $51.0(23.0)$ & $<0.01$ \\
\hline Sex, male, n (\%) & $56(75.7)$ & $1201(44.8)$ & $<0.01$ \\
\hline Race, Chinese, n (\%) & $65(87.8)$ & $1783(66.6)$ & $<0.01$ \\
\hline Body mass index, median (IQR), $\mathrm{kg} \mathrm{m}^{-2}$ & $24.1(5.1)$ & $23.6(5.5)$ & 0.29 \\
\hline \multicolumn{4}{|l|}{ Smoking status } \\
\hline Currently smoking, n (\%) & $26(35.1)$ & $335(12.5)$ & \multirow[t]{3}{*}{$<0.01$} \\
\hline Ex-smoker, n (\%) & $48(64.9)$ & $450(16.8)$ & \\
\hline Never smoked, n (\%) & $0(0)$ & $1894(70.7)$ & \\
\hline Alcohol drinkers, n (\%) & $48(65.8)$ & $1660(62.0)$ & 0.35 \\
\hline \multicolumn{4}{|l|}{ Education level } \\
\hline Secondary and below, n (\%) & $74(100)$ & $1352(50.5)$ & \multirow[t]{3}{*}{$<0.01$} \\
\hline Diploma or equivalent, n (\%) & $0(0)$ & $674(25.2)$ & \\
\hline Degree, n (\%) & $0(0)$ & $653(24.4)$ & \\
\hline Employed, n (\%) & $57(77.0)$ & $1798(67.1)$ & 0.07 \\
\hline \multicolumn{4}{|l|}{ Total monthly household income* } \\
\hline$<$ SGD \$2000, n (\%) & $12(16.2)$ & $633(23.6)$ & \multirow[t]{4}{*}{0.23} \\
\hline SGD \$2000-3999, n (\%) & $21(28.4)$ & $686(25.6)$ & \\
\hline SGD\$4000-5999, n (\%) & $17(23.0)$ & $481(18.0)$ & \\
\hline$\geq$ SGD\$6000, n (\%) & $24(32.4)$ & $629(23.5)$ & \\
\hline \multicolumn{4}{|l|}{ Co-morbidities } \\
\hline Hypertension, n (\%) & $11(14.9)$ & 499 (18.6) & 0.41 \\
\hline Diabetes mellitus, n (\%) & $3(4.1)$ & $246(9.2)$ & 0.09 \\
\hline Hyperlipidemia, n (\%) & $6(8.1)$ & $681(25.4)$ & $<0.01$ \\
\hline Coronary artery disease, n (\%) & $4(5.4)$ & $105(3.9)$ & 0.33 \\
\hline Chronic kidney disease, n (\%) & $2(2.7)$ & $18(0.67)$ & 0.10 \\
\hline \multicolumn{4}{|l|}{ WHO recommendations on physical activity for health } \\
\hline Meets WHO recommendations ${ }^{\dagger}, \mathrm{n}(\%)$ & $57(77.0)$ & $2403(89.7)$ & $<0.01$ \\
\hline Median time of total physical activity on average per day (IQR), minutes & $60(107.1)$ & $44.3(82.1)$ & 0.07 \\
\hline Median time spent on work-related physical activity on average per day (IQR), minutes & $0(31.0)$ & $0(34.3)$ & 0.38 \\
\hline Median time spent on travel-related physical activity on average per day (IQR), minutes & $13.6(36.4)$ & $20(34.3)$ & 0.07 \\
\hline Median time spent on recreational-related physical activity on average per day (IQR), minutes & $13.9(51.4)$ & $0(17.1)$ & 0.01 \\
\hline Doing no work-, transport-, or recreation-related physical activity, n (\%) & $9(12.2)$ & $240(9.0)$ & 0.34 \\
\hline \multicolumn{4}{|l|}{ WHO classification of physical activity level } \\
\hline Low level of physical activity, n (\%) & $17(23.0)$ & $1551(57.9)$ & \multirow[t]{3}{*}{$<0.01$} \\
\hline Moderate level of physical activity, n (\%) & $25(33.8)$ & $303(11.3)$ & \\
\hline High level of physical activity, n (\%) & $32(43.2)$ & $825(30.8)$ & \\
\hline High level of sedentary activity ${ }^{\S}, \mathrm{n}(\%)$ & $42(56.8)$ & $966(36.1)$ & $<0.01$ \\
\hline
\end{tabular}

\section{Abbreviation}

AxSpA Axial spondyloarthritis, IQR interquartile range, SGD Singapore dollar, WHO World Health Organization

*Some participants in the control group did not provide information on the household income.

tMeeting WHO recommendations on physical activity for health includes: (i) 150 min of moderate-intensity physical activity or (ii) 75 min of vigorous-intensity

physical activity or (iii) An equivalent combination of moderate- and vigorous-intensity physical activity achieving at least 600 MET-minutes

$\S$ Defined as more than $8 \mathrm{~h}$ of sedentary activity 
Table 2 Characteristics and physical activity levels between patients with axSpA with inactive vs low or high or very high disease activity

\begin{tabular}{|c|c|c|c|}
\hline Characteristics & $\begin{array}{l}\text { Inactive } \\
\text { disease } \\
N=27\end{array}$ & $\begin{array}{l}\text { Low, high or } \\
\text { very high } \\
\text { disease } \\
\text { activity } \\
N=47\end{array}$ & $P$ value \\
\hline Current age, median (IQR), years & $34.0(23.0)$ & $42.0(28.0)$ & 0.14 \\
\hline Sex, male, n (\%) & $19(70.4)$ & $37(78.7)$ & 0.42 \\
\hline Race, Chinese, n (\%) & $23(85.2)$ & $42(89.4)$ & 0.72 \\
\hline Body mass index, median (IQR), $\mathrm{kg} \mathrm{m}^{-2}$ & $22.6(5.2)$ & $24.3(4.9)$ & 0.06 \\
\hline \multicolumn{4}{|l|}{ Smoking status } \\
\hline Currently smoking, n (\%) & $8(29.6)$ & $18(38.3)$ & \multirow[t]{2}{*}{0.45} \\
\hline Ex-smoker, n (\%) & $19(70.4)$ & $29(61.7)$ & \\
\hline Alcohol drinkers, n (\%) & $17(63.0)$ & $31(67.4)$ & 0.70 \\
\hline BASFI (range 0-10), median (IQR) & $1.1(0.6)$ & $1.9(2.0)$ & $<0.01$ \\
\hline ASDAS-CRP (range 0-10), median (IQR) & $1.1(0.3)$ & $2.0(1.0)$ & $<0.01$ \\
\hline \multicolumn{4}{|l|}{ Co-morbidities } \\
\hline Hypertension, n (\%) & $4(14.8)$ & $7(14.9)$ & 1.00 \\
\hline Diabetes mellitus, n (\%) & $0(0)$ & $3(6.4)$ & 0.30 \\
\hline Hyperlipidemia, n (\%) & $2(7.4)$ & $4(8.5)$ & 1.00 \\
\hline Coronary artery disease, $\mathrm{n}(\%)$ & $1(3.7)$ & $3(6.4)$ & 1.00 \\
\hline Chronic kidney disease, n (\%) & $0(0)$ & $2(4.3)$ & 0.53 \\
\hline Employed, n (\%) & $22(81.5)$ & $35(74.5)$ & 0.49 \\
\hline \multicolumn{4}{|l|}{ WHO recommendations on physical activity for health } \\
\hline Meets $\mathrm{WHO}$ recommendations ${ }^{\dagger}, \mathrm{n}(\%)$ & $21(77.8)$ & $36(76.6)$ & 0.91 \\
\hline Median time of total physical activity on average per day (IQR), minutes & $68.6(145.7)$ & $57.9(85.7)$ & 0.46 \\
\hline Median time spent on work-related physical activity on average per day (IQR), minutes & $0(34.3)$ & $0(17.1)$ & 0.71 \\
\hline Median time spent on travel-related physical activity on average per day (IQR), minutes & $8.6(60.0)$ & $14.3(30.0)$ & 0.65 \\
\hline Median time spent on recreational-related physical activity on average per day (IQR), minutes & $12.9(64.3)$ & $15.0(42.9)$ & 0.37 \\
\hline Doing no work-, transport-, or recreation-related physical activity, n (\%) & $4(14.8)$ & $5(10.6)$ & 0.72 \\
\hline \multicolumn{4}{|l|}{ WHO level of physical activity } \\
\hline Low level of physical activity, n (\%) & $6(22.2)$ & $11(23.4)$ & \multirow[t]{3}{*}{0.47} \\
\hline Moderate level of physical activity, n (\%) & $7(25.9)$ & $18(38.3)$ & \\
\hline High level of physical activity, n (\%) & $14(51.9)$ & $18(38.3)$ & \\
\hline High level of sedentary activity ${ }^{\S}, \mathrm{n}(\%)$ & $18(66.7)$ & $24(51.1)$ & 0.19 \\
\hline
\end{tabular}

\section{Abbreviation}

ASDAS-CRP Ankylosing Spondylitis Disease Activity Score with C-Reactive Protein, AxSpA Axial spondyloarthritis, BASFI Bath Ankylosing Spondylitis Functional Index, IQR interquartile range, WHO World Health Organization

†Meeting WHO recommendations on physical activity for health includes: (i) 150 min of moderate-intensity physical activity or (ii) 75 min of vigorous-intensity physical activity or (iii) An equivalent combination of moderate- and vigorous-intensity physical activity achieving at least 600 MET-minutes $\S$ Defined as more than $8 \mathrm{~h}$ of sedentary

study by Haglund et al. using patient-reported physical activity level showed that $68 \%$ of patients with AS met WHO recommendations [22], compared to $65 \%$ in the general Swedish population. In a cross-sectional study in Paris based on self-reported physical activity level, $54.7 \%$ of the patients with axSpA met the WHO recommendations [21].
Interestingly, the levels of self-reported PA did not differ between patients with axSpA with inactive disease and patients with axSpA with active disease. A possible reason for this is although active disease has been shown to result in reduced physical activity [23], however, it is also possible that patients with more 
active disease may have been more motivated to exercise as demonstrated in the study by Falkenbach et al. [24], where patients with AS who were more disabled were found to exercise more frequently. Also, patients with axSpA with active disease might also have been encouraged by their rheumatologists to engage in physical activity since it is part of the numerous guidelines for the management of patients with axSpA with active disease $[10,25,26]$.

The high level of sedentary behaviour noted in the axSpA group compared to controls is worrying as sedentary activity has been linked to increased cardiovascular risk and death [27], and it is known that patients with axSpA are at higher risk of cardiovascular disease [28]. Increase in physical activity has been shown to attenuate cardiovascular risk [29], and should be encouraged in patients with axSpA.

There are several limitations to this paper. Firstly, the small sample size prevented analysis among the different ethnic groups apart from comparison between Chinese and non-Chinese patients. Secondly, as this was a cross-sectional study, we were not able to determine whether patients had higher levels of PA before the onset of disease. Thirdly, smokers and patients with lower educational levels might have been over-represented in our study due to the small sample size, as the proportion of smokers and distribution of educational levels in this study differed from our previous cohorts [30, 31]. Repeating the study with larger sample size will be needed. Fourthly, while the GPAQ is a validated questionnaire [32], it is a self-reported questionnaire, and thus a subjective evaluation, which may have led to overestimation of PA [33]. Lastly, as the axSpA and control groups were different in terms of sociodemographic characteristics, there may be confounding in our data, which could have biased the estimate towards or away from the null. Older participants were more likely to meet PA recommendations [13], while smoking was associated with lower exercise levels [34]. An additional limitation of the study is that the population data for the controls was collected in 2012 while the data for patients with axSpA was collected in 2016. We could not rule out the possibility of changes in PA levels due to changes in the environment in the different time period.

\section{Conclusion}

Although levels of PA did not differ between patients with active and inactive axSpA disease, patients with axSpA were less likely to meet the WHO recommendations for PA compared to the general population, and had higher levels of sedentary activity compared to the general population. This highlights the need for interventions to promote $\mathrm{PA}$ among patients with axSpA.

\section{Supplementary Information}

The online version contains supplementary material available at https://doi. org/10.1186/s41927-021-00211-5.

Additional file 1: Supplementary Table 1. Levels of activity of patients with axial spondyloarthritis with age-, gender-matched controls.

\section{Acknowledgements \\ The authors thank all the participants for their time and contribution to the study. We would also like to thank Prof Falk Müller-Riemenschneider and Saw Swee Hock School of Public Health, National University of Singapore for contributing the data for the controls. We would also like to thank Koh Hui Kai, Chua Chun En, Luo Yuxuan and Sophia Ng for their help in data collection.}

\section{Authors' contributions}

WF, YHK, and NCT conceptualized the study design, and drafted the survey questionnaire. JKP, AYKK, WF, YHK, NCT, and WF acquired the data. JKP, AYKK, and WF wrote the initial manuscript draft. All authors critically reviewed and approved the final manuscript.

Funding

There is no funding for this research.

\section{Availability of data and materials}

The datasets used and/or analysed during the current study are available from the corresponding author on reasonable request.

\section{Declarations}

Ethics approval and consent to participate

The SingHealth Centralized Institutional Review Board approved this study (Reference Number: 2016/2210). We obtained informed consent, which conformed to the principle outlined in the 1964 Declaration of Helsinki, from all participants before study commencement.

\section{Consent for publication}

Not applicable.

\section{Competing interests}

The authors declare that they have no competing interests.

\section{Author details}

${ }^{1}$ Department of Rheumatology and Immunology, Singapore General Hospital, Outram Rd, Singapore 169608, Singapore. ${ }^{2}$ Duke-NUS Medical School, 8 College Rd, Singapore 169857, Singapore. ${ }^{3}$ Department of Medicine, Yong Loo Lin School of Medicine, National University of Singapore, 10 Medical Dr, Singapore 117597, Singapore.

Received: 26 March 2021 Accepted: 21 June 2021

Published online: 31 August 2021

\section{References}

1. Braun J, Sieper J. Ankylosing spondylitis. Lancet. 2007;369(9570):1379-90. https://doi.org/10.1016/S0140-6736(07)60635-7.

2. Carette $S$, Graham D, Little H, Rubenstein J, Rosen P. The natural disease course of ankylosing spondylitis. Arthritis Rheum. 1983;26(2):186-90. https:// doi.org/10.1002/art.1780260210.

3. Salaffi F, Carotti M, Gasparini S, Intorcia M, Grassi W. The health-related quality of life in rheumatoid arthritis, ankylosing spondylitis, and psoriatic arthritis: a comparison with a selected sample of healthy people. Health Qual Life Outcomes. 2009;7:1-12.

4. Mathieu S, Gossec L, Dougados M, Soubrier M. Cardiovascular profile in ankylosing spondylitis: a systematic review and meta-analysis. Arthritis Care Res. 2011;63(4):557-63. https://doi.org/10.1002/acr.20364.

5. Bassuk SS, Manson JE. Physical activity and the prevention of cardiovascular disease. Curr Atheroscler Rep. 2003;5(4):299-307. https://doi.org/10.1007/s11 883-003-0053-7. 
6. Caspersen CJ, Powell KE, Christenson GM. Physical activity, exercise, and physical fitness: definitions and distinctions for health-related research. Public Health Rep. 1985;100:126.

7. Garber CE, Blissmer B, Deschenes MR, Franklin BA, Lamonte MJ, Lee I-M, Nieman DC, Swain DP: Quantity and quality of exercise for developing and maintaining cardiorespiratory, musculoskeletal, and neuromotor fitness in apparently healthy adults: guidance for prescribing exercise. 2011

8. Bull FC, Al-Ansari SS, Biddle S, Borodulin K, Buman MP, Cardon G, et al. World Health Organization 2020 guidelines on physical activity and sedentary behaviour. Br J Sports Med. 2020;54(24):1451-62. https://doi.org/1 0.1136/bjsports-2020-102955

9. Sveaas SH, Berg IJ, Provan SA, Semb AG, Hagen KB, Vøllestad N, et al. Efficacy of high intensity exercise on disease activity and cardiovascular risk in active axial spondyloarthritis: a randomized controlled pilot study. PLoS One. 2014;9(9):e108688. https://doi.org/10.1371/journal.pone.0108688.

10. Rausch Osthoff AK, Niedermann K, Braun J, Adams J, Brodin N, Dagfinrud H, et al. EULAR recommendations for physical activity in people with inflammatory arthritis and osteoarthritis. Ann Rheum Dis. 2018;2018(77): 1251-60.

11. Sundstrom B, Ekergård $H$, Sundelin $G$. Exercise habits among patients with ankylosing spondylitis. Scand J Rheumatol. 2002;31(3):163-7. https://doi. org/10.1080/rhe.31.3.163.167.

12. Passalent LA, Soever LJ, O'SHEA FD, Inman RD. Exercise in ankylosing spondylitis: discrepancies between recommendations and reality. J Rheumatol. 2010;37(4):835-41. https://doi.org/10.3899/jrheum.090655.

13. Win AM, Yen LW, Tan KHX, Lim RBT, Chia KS, Mueller-Riemenschneider F. Patterns of physical activity and sedentary behavior in a representative sample of a multi-ethnic south-east Asian population: a cross-sectional study. BMC Public Health. 2015;15(1):318. https://doi.org/10.1186/s12889-01 5-1668-7.

14. Lukas C, Landewé R, Sieper J, Dougados M, Davis J, Braun J, et al. Development of an ASAS-endorsed disease activity score (ASDAS) in patients with ankylosing spondylitis. Ann Rheum Dis. 2009;68(1):18-24 https://doi.org/10.1136/ard.2008.094870.

15. Calin A, Garrett S, Whitelock H, Kennedy LG, O'hea J, Mallorie P, et al. A new approach to defining functional ability in ankylosing spondylitis: the development of the Bath ankylosing spondylitis functional index. J Rheumatol. 1994;21:2281-5.

16. Bull FC, Maslin TS, Armstrong T. Global physical activity questionnaire (GPAQ): nine country reliability and validity study. J Phys Act Health. 2009: 6(6):790-804. https://doi.org/10.1123/jpah.6.6.790.

17. Hamrik Z, Sigmundová D, Kalman M, Pavelka J, Sigmund E. Physical activity and sedentary behaviour in Czech adults: results from the GPAQ study. Eur J Sport Sci. 2014;14(2):193-8. https://doi.org/10.1080/1 7461391.2013.822565

18. Van der Ploeg HP, Chey T, Korda RJ, Banks E, Bauman A. Sitting time and allcause mortality risk in 222497 Australian adults. Arch Intern Med. 2012; 172(6):494-500. https://doi.org/10.1001/archinternmed.2011.2174.

19. Swinnen TW, Scheers T, Lefevre J, Dankaerts W, Westhovens R, de Vlam K. Physical activity assessment in patients with axial spondyloarthritis compared to healthy controls: a technology-based approach. PLoS One. 2014;9(2):e85309. https://doi.org/10.1371/journal.pone.0085309.

20. Plasqui G, Boonen A, Geusens P, Kroot E, Starmans M, Van Der Linden S. Physical activity and body composition in patients with ankylosing spondylitis. Arthritis Care Res. 2012;64(1):101-7. https://doi.org/10.1002/acr.20566.

21. Fabre S, Molto A, Dadoun S, Rein C, Hudry C, Kreis S, et al. Physical activity in patients with axial spondyloarthritis: a cross-sectional study of 203 patients. Rheumatol Int. 2016;36(12):1711-8. https://doi.org/10.1007/s00296016-3565-5

22. Haglund E, Bergman S, Petersson IF, Jacobsson LT, Strömbeck B, Bremander A. Differences in physical activity patterns in patients with spondylarthritis. Arthritis Care Res. 2012;64(12):1886-94. https://doi.org/10.1002/acr.21780.

23. Fongen $\mathrm{C}$, Halvorsen S, Dagfinrud H. High disease activity is related to low levels of physical activity in patients with ankylosing spondylitis. Clin Rheumatol. 2013;32(12):1719-25. https://doi.org/10.1007/s10067-013-2320-5.

24. Falkenbach $\mathrm{A}$. Disability motivates patients with ankylosing spondylitis for more frequent physical exercise. Arch Phys Med Rehabil. 2003;84(3):382-3. https://doi.org/10.1053/apmr.2003.50013.

25. Ward MM, Deodhar A, Gensler LS, Dubreuil M, Yu D, Khan MA, et al. Update of the American College of Rheumatology/spondylitis Association of America/Spondyloarthritis research and treatment network recommendations for the treatment of ankylosing spondylitis and nonradiographic axial Spondyloarthritis. Arthritis Rheumatol. 2019;2019(71): 1599-613.

26. van der Heijde D, Ramiro S, Landewé R, Baraliakos X, Van den Bosch F, Sepriano A, et al. Update of the ASAS-EULAR management recommendations for axial spondyloarthritis. Ann Rheum Dis. 2016;2017(76): 978-91.

27. Wilmot EG, Edwardson CL, Achana FA, Davies MJ, Gorely T, Gray LJ, et al. Sedentary time in adults and the association with diabetes, cardiovascular disease and death: systematic review and meta-analysis. Diabetologia. 2012; 55(11):2895-905. https://doi.org/10.1007/s00125-012-2677-z.

28. Papagoras C, Markatseli TE, Saougou I, Alamanos Y, Zikou AK, Voulgari PV, et al. Cardiovascular risk profile in patients with spondyloarthritis. Joint Bone Spine. 2014;81(1):57-63. https://doi.org/10.1016/j.jbspin.2013.03.019.

29. Fenton SA, van Zanten JJV, Kitas GD, Duda JL, Rouse PC, Yu C-A, et al. Sedentary behaviour is associated with increased long-term cardiovascular risk in patients with rheumatoid arthritis independently of moderate-tovigorous physical activity. BMC Musculoskelet Disord. 2017;18:1-12.

30. Goh Y, Kwan YH, Leung YY, Fong W, Cheung PP. A cross-sectional study on factors associated with poor work outcomes in patients with axial spondyloarthritis in Singapore. Int J Rheum Dis. 2019;22(11):2001-8. https:// doi.org/10.1111/1756-185X.13696.

31. Png WY, Kwan YH, Lee YX, Lim KK, Chew EH, Lui NL, et al. Factors associated with initiation of biologics in patients with axial spondyloarthritis in an urban Asian City: a PRESPOND study. JCR J Clin Rheumatol. 2019;25(2): 59-64. https://doi.org/10.1097/RHU.0000000000000762.

32. Keating XD, Zhou K, Liu X, Hodges M, Liu J, Guan J, et al. Reliability and concurrent validity of global physical activity questionnaire (GPAQ): a systematic review. Int J Environ Res Public Health. 2019;16(21):4128. https:// doi.org/10.3390/ijerph16214128.

33. Harris TJ, Owen CG, Victor CR, Adams R, Ekelund U, Cook DG. A comparison of questionnaire, accelerometer, and pedometer: measures in older people. Med Sci Sports Exerc. 2009;41(7):1392-402. https://doi.org/10.1249/MSS. Ob013e31819b3533.

34. Conway TL, Cronan TA. Smoking, exercise, and physical fitness. Prev Med. 1992;21(6):723-34. https://doi.org/10.1016/0091-7435(92)90079-W.

\section{Publisher's Note}

Springer Nature remains neutral with regard to jurisdictional claims in published maps and institutional affiliations.
Ready to submit your research? Choose BMC and benefit from:

- fast, convenient online submission

- thorough peer review by experienced researchers in your field

- rapid publication on acceptance

- support for research data, including large and complex data types

- gold Open Access which fosters wider collaboration and increased citations

- maximum visibility for your research: over $100 \mathrm{M}$ website views per year

At $\mathrm{BMC}$, research is always in progress.

Learn more biomedcentral.com/submission 